\title{
Colour Reflectance Investigation of Decolourized Sulfur Dyed Cotton Knitted Fabric via Ozone Plasma Treatment
}

\author{
Yaohui Liu1 ${ }^{*}$, Yanming Wang1, Hiu-Yan Cheung2, Chi-Wai Kan², Hong Chua1 \\ ${ }^{1}$ Department of Construction Technology and Engineering, The Technological and Higher Educational Institute of Hong Kong, \\ Tsing Yi, New Territories, Hong Kong, China \\ ${ }^{2}$ Institute of Textiles and Clothing, The Hong Kong Polytechnic University, Hung Hom, Kowloon, Hong Kong, China \\ Email: *yhliu@vtc.edu.hk
}

How to cite this paper: Liu, Y.H., Wang, Y.M., Cheung, H.-Y., Kan, C.-W. and Chua, H. (2020) Colour Reflectance Investigation of Decolourized Sulfur Dyed Cotton Knitted Fabric via Ozone Plasma Treatment. World Journal of Engineering and Technology, 8, 429-442.

https://doi.org/10.4236/wjet.2020.83032

Received: July 12, 2020

Accepted: August 9, 2020

Published: August 12, 2020

\begin{abstract}
Ozone plasma treatment is accessible to be applied on shading adjustment and colour fading because of the capacity of ozone production. It is a green process that treats dyed cotton fabric under dry condition so as to avoid chemical pollutants. This study means to explore colour reflectance of decolourized sulfur dyed cotton texture using ozone plasma treatment. Sulfur dyed cotton textures with various colour depths $(0.5 \%, 1.5 \%, 2.5 \%)$ were set up to be treated different plasma parameters, including ozone air concentrations $(10 \%, 30 \%$, $50 \%, 70 \%)$, water contents in terms of weight percentage (35\%, 45\%) of fabric and ozone air plasma treatment periods ( $10 \mathrm{mins}, 20 \mathrm{mins}, 30 \mathrm{mins})$. The colour fading result is assessed by the colour reflectance in percentage (R\%) utilizing spectrophotometer under CIE standard illuminant D65. The valid colour fading based on high percentage of reflectance was demonstrated from plasma treatment under higher ozone air concentration $(50 \%$ and $70 \%$ ozone in air) and longer time length of plasma treatment (20 mins and $30 \mathrm{mins})$. The level of water content contained in the cotton fabrics is appeared to have noteworthy relationship with the degree of decolourization.
\end{abstract}

\section{Keywords}

Plasma Treatment, Cotton Fabric, Colour Reflectance, Sulfur Dye, Decolourization

\section{Introduction}

Colour fading or decolourization is an indispensable textile finishing technique that can give a stylish appearance by adding acceptable worn look fabric tex- 
tures, and providing more options to clients. Notwithstanding, some conventional colour fading technologies such as acid washing and bleaching which contaminate enormous amount of water with chemical concoctions utilized in process [1]. At the same time, the use of regular pumice stones has experienced problems in the removal of residual pumice from prepared attire items and the reduction of textural strength of textile fabrics [2], may cause some ecological issues in process. The textile industry faces the requirements to address its duty toward a wide scope of health and ecological issues. Low temperature plasma treatment with air contains clear yield during process and with eco-accommodating setting with no toxic pollutant discharge and reduction of handling time has been presented.

Ozone plasma treatment has been a compelling strategy for surface modification of textile fabrics by a dry etching process [3] [4]. According to the eco-friendly nature of plasma, a specific benefit of ozone plasma treatment over other traditional textile finishing strategies is the likelihood to control the process parameters including ozone concentration in air, water content and time length for plasma treatment. Just as altering the morphology and surface chemical structure of the fiber [5], the impact of plasma treatment on the colour fading level of $100 \%$ sulfur dyed cotton knitted fabrics were examined in this study. The colour shading properties of plasma-treated cotton fabrics were also evaluated from the measurement of colour reflectance data $(\mathrm{R} \%)$ in visible range.

\section{Materials and Methods}

\subsection{Materials}

The fabrics utilized in this examination were $100 \%$ cotton single jersey knitted fabrics (220 gram 32/2) dyed with Diresul ${ }^{\circledR}$ RDT liquid red sulfur dye in colour depths of $0.5 \%, 1.5 \%$ and $2.5 \%$, respectively.

\subsection{Dyeing Receipe}

As described in Figure 1, 10\% - 12\% Reductor D Powder, 10\% - 12\% Caustic Soda 50\%, 1 - 2 g/L Ladiquest ${ }^{\circledR} 2005$ liq and $1-2$ g/L LeoniI ${ }^{\circledR}$ EHC liq were added in the dyeing bath at $600 \mathrm{o}$. After 10 mins, Diresul ${ }^{\circledR}$ Liquid Red RDT Dyestuff was further added for about 20 mins. The temperature of the dyeing bath was then raised to $70-75^{\circ} \mathrm{C}$. After $10 \mathrm{mins}$, one-third of $30-40 \mathrm{~g} / \mathrm{L}$ Sodium Sulphate was added and stayed for 30 mins at an interval of 5 mins.

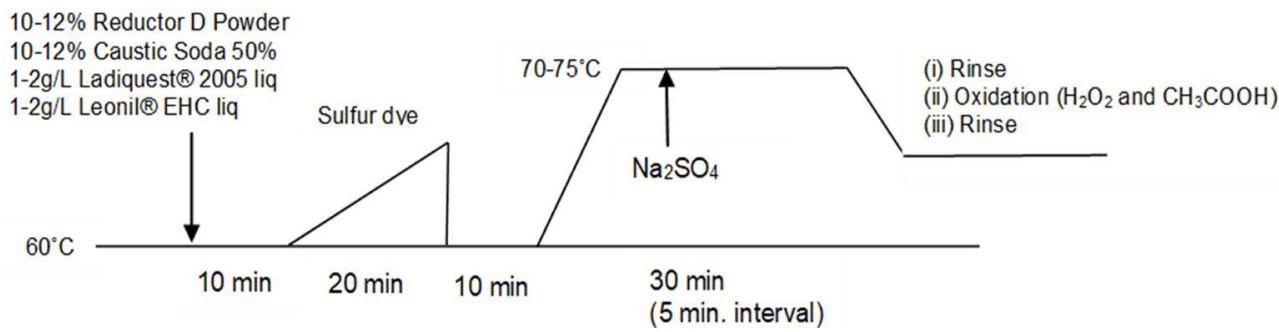

Figure 1. Dyeing profile of sulfur dye (red). 
The sulfur dyed cotton fabric was subsequently overflow rinsed until clear and the bath temperature was decreased to $50^{\circ} \mathrm{C}$ for oxidation process. The oxidation process was performed in solution at $\mathrm{pH} 4-4.5$ for $15-20$ mins using $2 \%-4 \%$ Hydrogen Peroxide (35\% purity) and $2 \%$ Acetic Acid (80\% purity). The sulfur dyed fabric was then treated with $2 \mathrm{~g} / \mathrm{L}$ soda ash at $90^{\circ} \mathrm{C}$ for $10 \mathrm{mins}$. Finally, the dyed fabrics after colour fixation process were thoroughly rinsed with water and air-dried completely.

\subsection{Apparatus}

The plasma fading machine "G2", which is created by "Jeanologia", a Spanish historical technology development company, was selected to carry out in the plasma treatment. According to the information provided by "Jeanologia", "G2" is an environmental friendly washing machine that contains innovative technology conceivably saving $60 \%$ of power and water, $40 \%$ of treatment time and $80 \%$ of chemical products comparing with the conventional washing strategies.

\subsection{Plasma Treatment}

Subsequent to dyeing, rinsing and drying, the cotton fabrics in various colour depths were separated into 25 pieces and then handled by Jeanologia G2 machine. For each colour depth experiment, leaving a small piece of control fabric as a control sample, each of the rest samples was treated under a combination of the parameters recorded in Table 1 , totally 24 combinations in a batch.

There were totally 72 pieces of cotton knitted fabrics are plasma-treated using G2 machine. The cotton knitted fabrics were partitioned into 3 sets that have been dyeing in three colour depths $(0.5 \%, 1.5 \%$ and $2.5 \%)$. The plasma treatment was carried out in the atmospheric pressure by transforming the air into mixture of reactive oxygen and ozone. The resultant chemical components were considered as bleaching agents with controlled $\mathrm{H}_{2} \mathrm{O}$ addition to treated fabrics as shown in Figure 2.

Table 1. Summary of condition and parameters used in the plasma treatment.

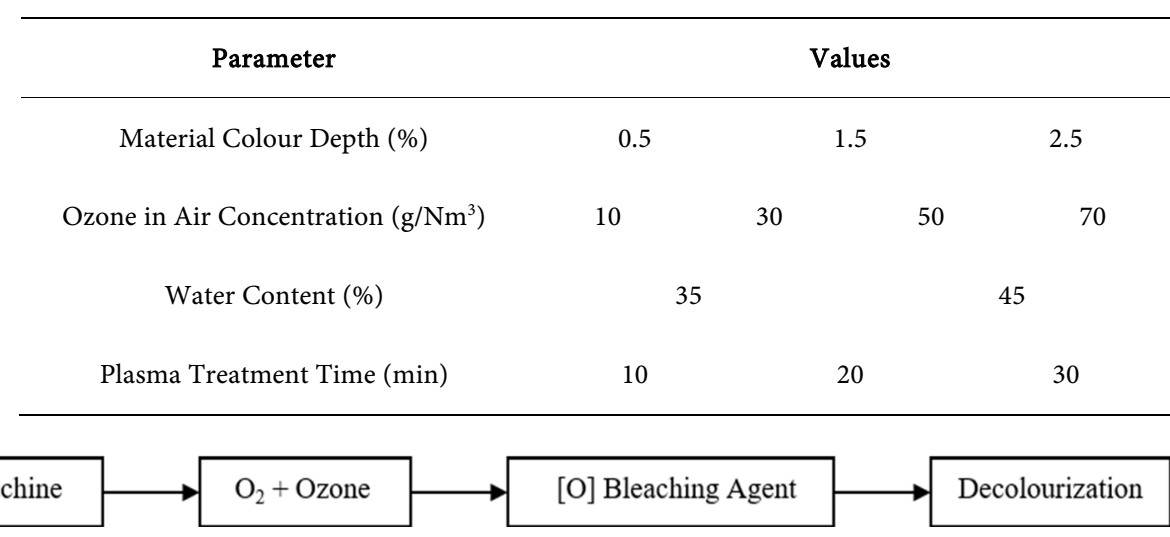

Figure 2. Colour fading process by G2 plasma treatment. 
In the plasma treatment, the fabrics were placed inside the G2 machine with various programmable parameter settings. The parameters utilized in the plasma process, including input ozone air concentration $(10 \%, 30 \%, 50 \%, 70 \%)$, water content, were based on moisture uptake of fabric samples $(35 \%, 45 \%)$ and time required for plasma treatment $(10 \mathrm{~min}, 20 \mathrm{~min}, 30 \mathrm{~min})$. The parameters are summarized in Table 1 and only a single parameter was changed while the other parameters were kept constant. The plasma density generated is proportional to the ozone concentration in air. Treatment time is the time required for the whole plasma treatment of cotton fabric. Water content is the weight percentage of water to fabric in the decolourization process.

\subsection{Colour Reflectance Measurement}

Colour measurements were conducted by a colour testing machine, Macbeth ColorEye 7000 A Spectrophotometer (GretagMacbeth, Australia), using a large aperture size with illuminant source D65. The plasma treated fabric was folded twice to ensure $100 \%$ opacity and measured for 2 times. After the first measurement, the fabric was rotated 90 degree and measured a second time. In this manner, both warp and weft directions were measured accordingly. Reflectance $\%$ values were recorded on the computer.

\section{Results and Discussion}

\subsection{Comparison the Results between Various Treatment Times in Same Group of Colour Depth and Water Content}

\section{1) $0.5 \%$ Colour Depth Group}

From Figure 3, as indicated from the first 10 mins, $70 \%$ air concentration has higher colour fading strength than $50 \%$ air concentration in both water content conditions. However, the difference is greater with $35 \%$ water content. Higher air concentration can upgrade the mass transfer properties of ozone. The colour fading strength is higher with $45 \%$ water content. It is on the grounds ozone arrives at the saturation level in water more rapidly with $35 \%$ water content and overdose lessens the reaction rate among ozone and dye chromophores. Higher air concentration additionally accelerates the saturation level so $30 \%$ air concentration with $35 \%$ water content can have a higher colour fading strength than $50 \%$ and $70 \%$ air concentrations under $35 \%$ water content (Table 2).

From 10 to 20 mins, ozone in treatment of $30 \%$ air concentration with $35 \%$ water content has saturated and thus the quality of colour fading strength decreases. Throughout the treatment process, higher air concentration has higher colour fading strength in both water content as all parameters related to air concentration have experienced the decay of reaction rate.

From 20 to 30 mins, colour fading strengths in 30\% air concentration with $35 \%$ water content, $50 \%$ and $70 \%$ air concentrations with $45 \%$ water content increases while $50 \%$ and $70 \%$ air concentrations with $35 \%$ water content keep diminishing. Ozone can stay in water for around 20 mins before it decomposes [6]. 

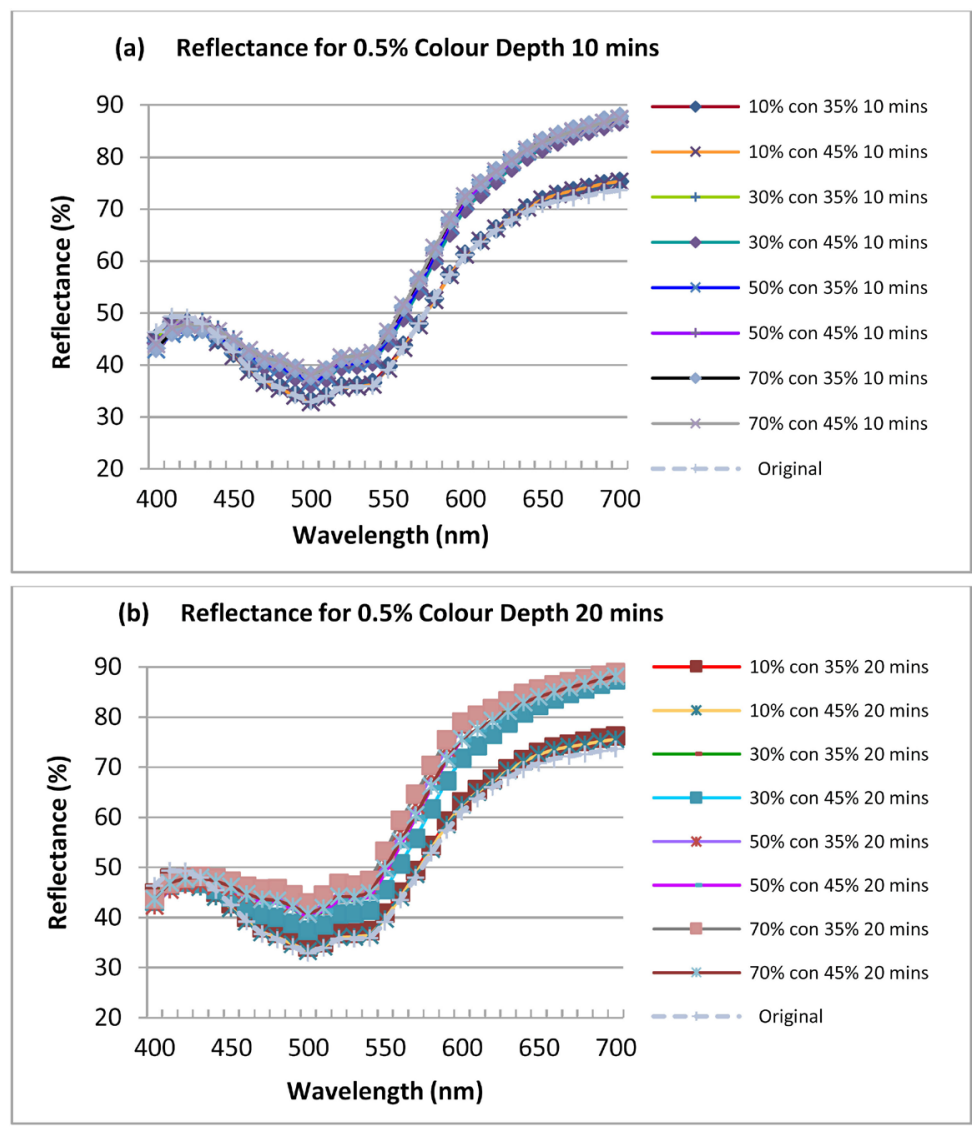

(c) Reflectance for $0.5 \%$ Colour Depth 30 mins

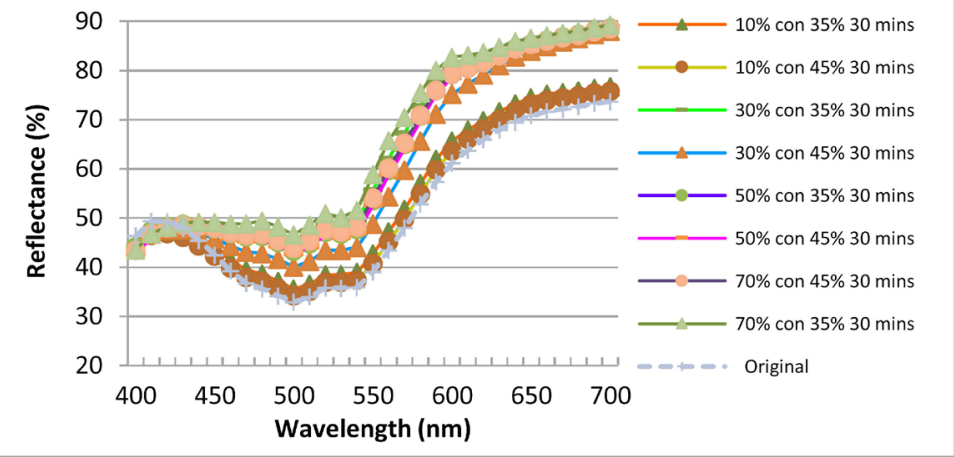

Figure 3. Reflectance curves of untreated sulfur dyed cotton samples and plasma treated dyed cotton samples in $0.5 \%$ colour depth under various air concentrations with treatment time of (a) 10 mins, (b) 20 mins and (c) 30 mins.

Table 2. Top 5 colour fading results descending rankings in different treatment time ( $0.5 \%$ colour depth).

\begin{tabular}{cc}
\hline & $\begin{array}{c}\text { Top } 5 \text { Ranking } \\
\text { Treatment time }\end{array}$ \\
$\begin{array}{c}(\%=\text { Air concentration with } 35 \% \text { water content }) \\
(\%=\text { Air concentration with } 45 \% \text { water content })\end{array}$ \\
\hline 10 mins & $70 \% \rightarrow 70 \% \rightarrow 50 \% \rightarrow 30 \% \rightarrow 50 \%$ \\
20 mins & $70 \% \rightarrow 50 \% \rightarrow 70 \% \rightarrow 30 \% \rightarrow 50 \% ’$ \\
30 mins & $70 \% \rightarrow 30 \% \rightarrow 70 \% \rightarrow 50 \% \rightarrow 50 \% ’$ \\
\hline
\end{tabular}


After a portion of the ozone decomposes, again there is space available for fresh ozone to dissolve and exhibit an increment in the reaction rate. As dissolution of ozone in $30 \%$ air concentration or in $45 \%$ water content is slower than the higher concentrations of $50 \%$ and $70 \%$ air concentrations with $35 \%$ water content, there is more time available for fast and effective reactions between ozone with dye chromophores before the occurrence of next ozone saturation. Hence, increments in colour fading strengths preferentially occurred at lower air concentrations.

\section{2) $1.5 \%$ Colour Depth Group}

As indicated from 1.5\% colour depth group in Figure 4, during the first 10 mins, with both $35 \%$ and $45 \%$ water content, the air concentration is proportional to the colour fading power due to increase in mass transfer rate. Moreover, the colour fading strengths are observed to be weakened at higher water content due to only a limited portion of ozone reacts with dye chromophores on the fabric surface within 10 mins (Table 3).

Between 10 and 20 mins, with both $35 \%$ and $45 \%$ water content, the air concentration is inversely proportional to the power of colour fading. It is evident to observe from $50 \%$ and $70 \%$ air concentrations. The factor may be due to ozone saturation in water medium and overdose level may slow down the rate of reaction. In lower water content (35\%), higher air concentration accelerates the saturation process and thereby decreasing the colour fading strength. In higher water content (45\%), the colour fading strength of $70 \%$ air concentration is higher than that of $50 \%$ air concentration. The saturation level of both air concentrations may have reached within 20 mins treatment length.

From 20 to 30 mins, the colour fading strength of higher air concentration (70\%) keeps increasing at long treatment time. The increment in colour fading strength may be due to sufficient time for degradation of ozone thus providing more room for fresh ozone dissolution and further improving the rate of colour fading reaction. Furthermore, the colour fading strengths of both $30 \%$ and $50 \%$ air concentrations keep decreasing simply because the time required to reach the saturation level is longer and the dissolved ozone is not yet to decompose in sufficient quantity for effective colour fading process.

\section{3) $2.5 \%$ Colour Depth Group}

As illustrated in Figure 5, in both 35\% and 45\% water content conditions, the air concentration is proportional to the colour fading power in the first 10 mins due to increase in mass transfer rate. However, for $45 \%$ water content, the colour fading strength is relatively lower than that with $35 \%$ water content. This is probably due to longer time requirement for saturation of ozone molecules in water and further interaction with the dye chromophores on the fabric (Table 4).

From 10 to 20 mins, with $35 \%$ water content, the air concentration is shown to be inversely proportional to the power of colour fading. The medium $50 \%$ air concentration shows relatively better fading strength compared to $70 \%$ and $30 \%$ air concentrations. It is because higher ozone concentration accelerates the saturation process and excess ozone in water is able to slow down the reaction rate. In lower ozone concentration (30\%), the saturation level can be improved but 

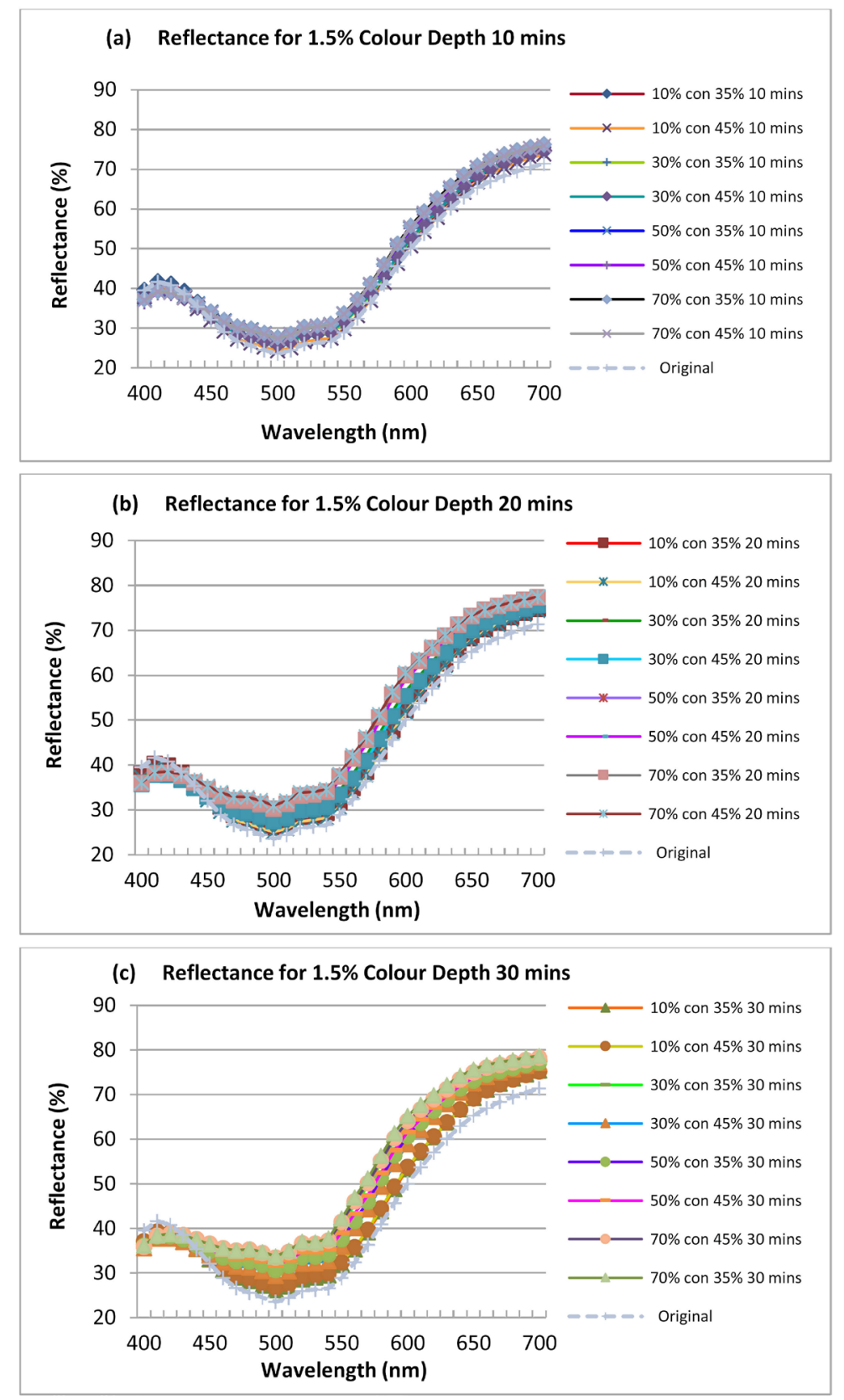

Figure 4. Reflectance curves of untreated sulfur dyed cotton samples and plasma treated dyed cotton samples in $1.5 \%$ colour depth under various air concentrations with treatment time of (a) 10 mins, (b) 20 mins and (c) 30 mins.

Table 3. Top 5 colour fading results descending rankings in different treatment time (1.5\% colour depth).

\begin{tabular}{cc}
\hline & $\begin{array}{c}\text { Top } 5 \text { Ranking } \\
\text { Treatment time }\end{array}$ \\
$\begin{array}{c}(\%=\text { Air concentration with } 35 \% \text { water content }) \\
(\%=\text { Air concentration with } 45 \% \text { water content })\end{array}$ \\
\hline 10 mins & $70 \% \rightarrow 50 \% \rightarrow 70 \% \rightarrow 50 \% \rightarrow 30 \% ’$ \\
20 mins & $70 \% \rightarrow 50 \% \rightarrow 70 \% \rightarrow 50 \%$ ' $\rightarrow 30 \%$ \\
30 mins & $70 \% \rightarrow 70 \%{ }^{\prime} \rightarrow 30 \% \rightarrow 50 \%$ ' $\rightarrow 50 \%$ \\
\hline
\end{tabular}



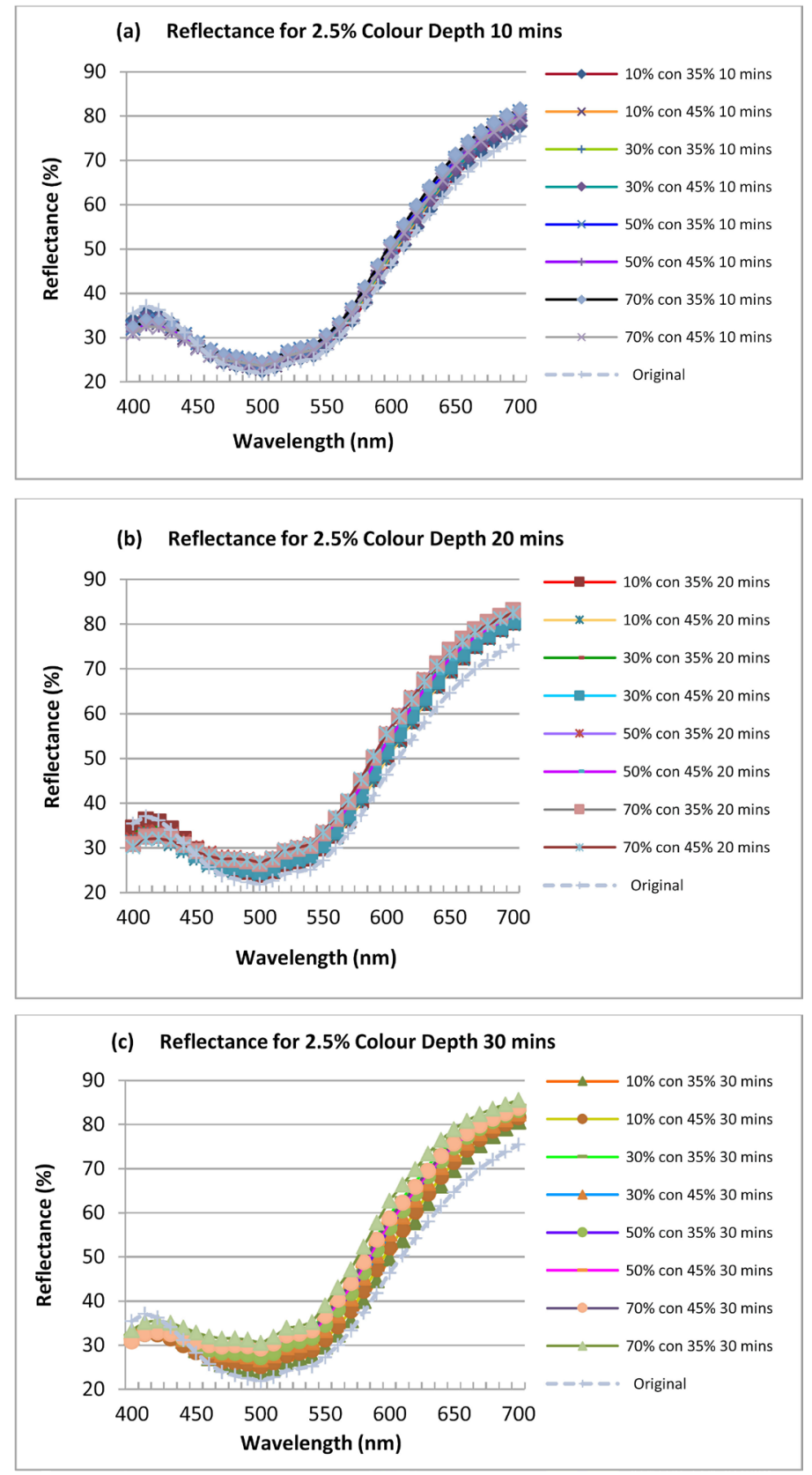

Figure 5. Reflectance curves of untreated sulfur dyed cotton samples and plasma treated dyed cotton samples in $2.5 \%$ colour depth under various air concentrations with treatment time of (a) 10 mins, (b) 20 mins and (c) 30 mins.

Table 4. Top 5 colour fading results descending rankings in different treatment time (2.5\% colour depth).

Top 5 Ranking

Treatment time $\quad(\%=$ Air concentration with $35 \%$ water content $)$

(\%' = Air concentration with $45 \%$ water content)

\begin{tabular}{ll}
\hline 10 mins & $70 \% \rightarrow 50 \% \rightarrow 30 \% \rightarrow 50 \%^{\prime} \rightarrow 70 \%$ \\
20 mins & $50 \% \rightarrow 70 \%{ }^{\prime} \rightarrow 70 \% \rightarrow 30 \% \rightarrow 50 \%$ \\
30 mins & $70 \% \rightarrow 30 \% \rightarrow 70 \% \%^{\prime} \rightarrow 50 \%{ }^{\prime} \rightarrow 50 \%$ \\
\hline
\end{tabular}


the time required for sufficient degree of ozone decomposition for colour fading reaction is expected to be longer. In $45 \%$ water content condition, higher air concentration (70\%) exhibits better colour fading results than lower air concentration (50\%). As there is more room for ozone to dissolve and sufficient amount of decomposed ozone are required for interaction with dye chromophores, reaction rate has not yet been achieved during this period.

From 20 to 30 mins, in $35 \%$ water content, the colour fading strength of both $30 \%$ and $50 \%$ air concentrations decreases significantly due to sufficient time for full ozone saturation. The condition in $45 \%$ water content showed similar trend as $35 \%$ water content. As for $70 \%$ air concentration under the condition of $35 \%$ water content, the early dissolved ozone has sufficient time for decomposition and more space available for additional ozone dissolution. Therefore, the reaction between ozone or reactive oxygen and dye chromophores are faster and the colour fading property is improved. It is even better in decolourization strength in terms of colour reflectance (R\%) compared with the mass transfer kinetics within 10 mins because there is no reactivation requirement for the initial mass transfer process.

\subsection{Comparison the Results between Ozone Air Concentration in Same Group of Colour Depth and Water Content}

\section{1) Effect of Ozone Air Concentration (0.5\% Colour Depth)}

For cases in $0.5 \%$ colour depth group of the similar treatment time and water content in Figure 6, colour depth normally decreases corresponding to increment
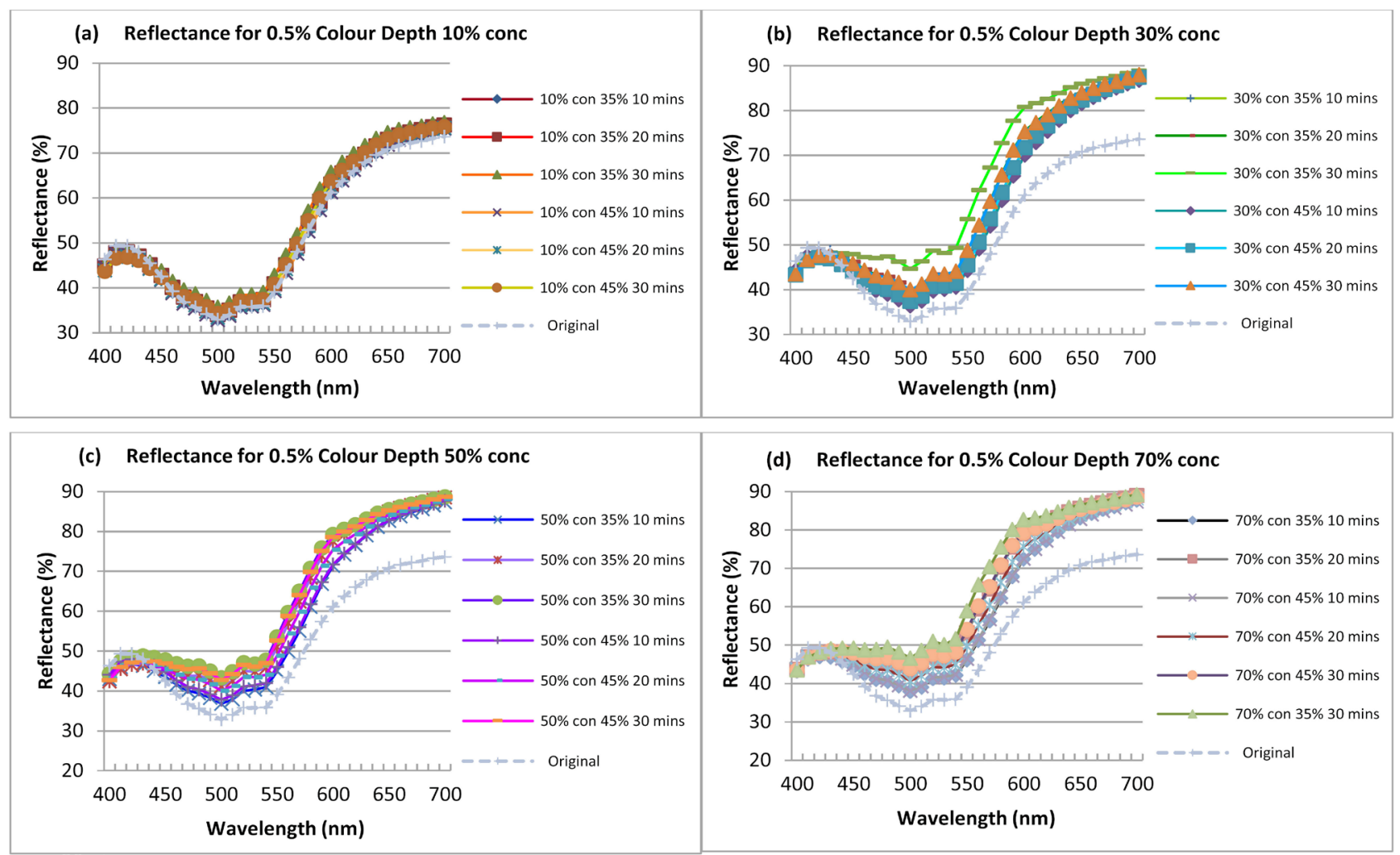

Figure 6. Reflectance Curves of untreated sulfur dyed cotton samples and plasma treated dyed cotton samples in $0.5 \%$ colour depth under various treatment times with air concentration of (a) $10 \%$; (b) $30 \%$; (c) $50 \%$ and (d) $70 \%$. 
of ozone air concentration. However, in 10 and 30 mins treatments under $35 \%$ water content, $30 \%$ air concentration yields stronger colour fading results compared with $50 \%$ air concentration. The colour fading strength of $10 \%$ air concentration fades is much weaker than other ozone air concentrations through the whole stage of plasma treatment. $70 \%$ air concentration treatment with $35 \%$ water content provides the best colour fading results. Higher air concentration does not necessarily provide better colour fading than lower air concentration and the colour fading effect is mainly water content dependent.

\section{2) Effect of Ozone Air Concentration (1.5\% Colour Depth)}

As illustrated in Figure 7, the colour fading power of $10 \%$ air concentration is the lowest during the whole treatment process, whereas the strongest colour fading condition is $70 \%$ air concentration with $35 \%$ water content. At the initial stage, the colour fading power is weak for lower air concentrations ( $10 \%$ and $30 \%)$. Nevertheless, the colour fading power increases rapidly with time and finally the results are beyond $10 \%$ air concentration. The result of $30 \%$ air concentration with $35 \%$ water content is highly comparable to $70 \%$ air concentration with $45 \%$ water content in 30 mins treatments. For the condition of $45 \%$ water content, the ozone air concentration is direct proportional to colour fading result based on colour reflectance data. However, in 35\% water content, 50\% air concentration showed comparable result as $70 \%$ after 20 mins plasma treatment.
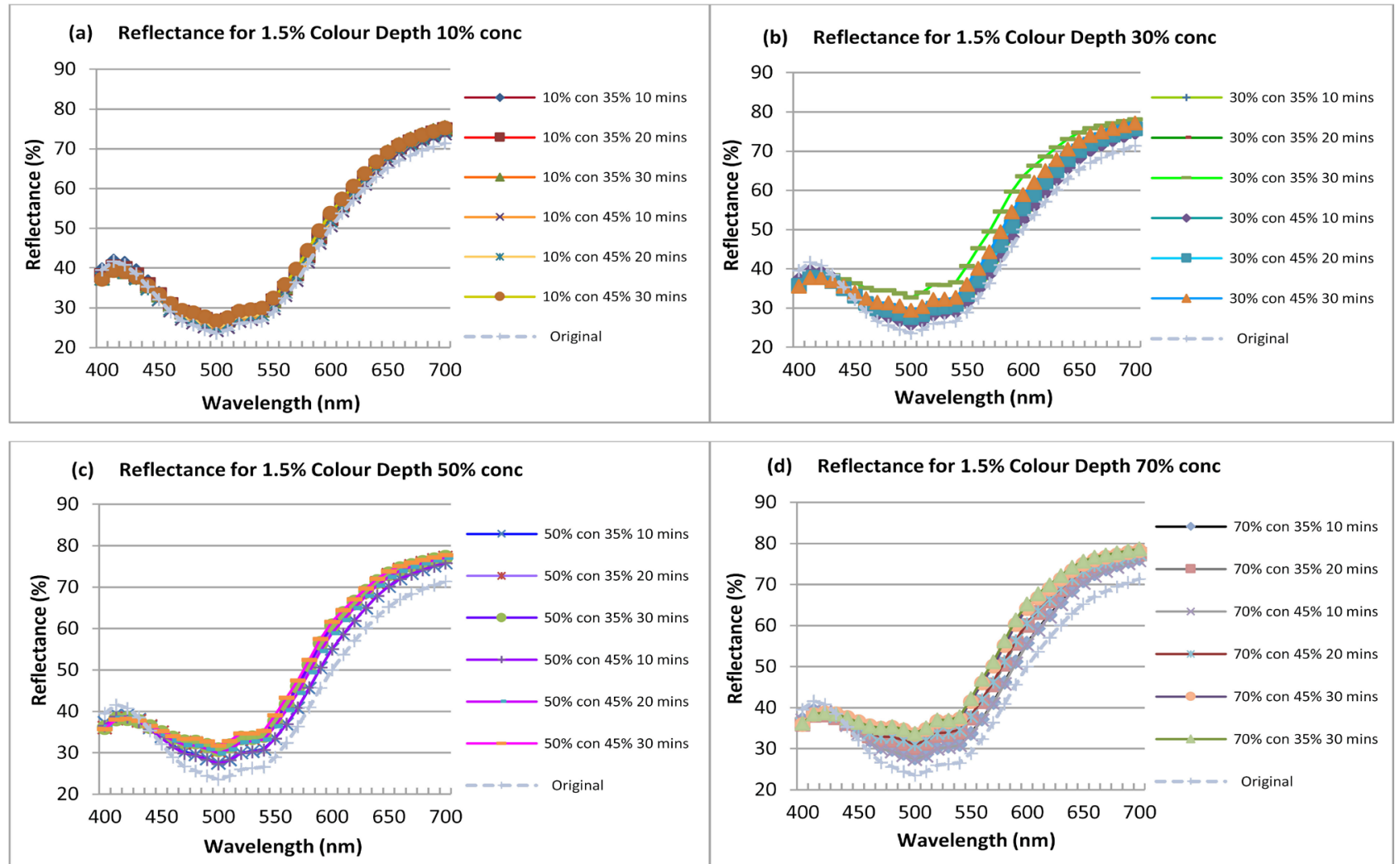

Figure 7. Reflectance Curves of untreated sulfur dyed cotton samples and plasma treated dyed cotton samples in $1.5 \%$ colour depth under various treatment times with air concentration of (a) $10 \%$; (b) $30 \%$; (c) $50 \%$ and (d) $70 \%$. 
As plasma treatment time extends to 30 mins, the colour fading strength in $30 \%$ ozone air concentration becomes higher than that of $50 \%$ ozone air concentration treatment due to the amount of decomposed ozone available for effective decolorization. There are evidences showing that lower air concentration fade more than higher air concentration through adjustment of water content.

\section{3) Effect of Ozone Air Concentration (2.5\% colour depth)}

$10 \%$ air concentration is shown to be the lowest colour fading strength under various treatment time, as indicated in Figure 8. The colour fading strength indeed depends on amount of decomposed ozone generated for bleaching of coloured fabric. Lower ozone air concentrations are able to achieve better colour fading results than higher ozone air concentrations by controlling the saturation level and decomposition rate of ozone in water during plasma treatment.

\subsection{Comparison of the Results of Fabrics Contained Different Water Content in the Plasma Treatment and Dyed in the Same Colour Depth}

\section{1) Effect of Water Content in $\mathbf{0 . 5 \%}$ Colour Depth}

Colour depth generally decreases more under $35 \%$ water content at treatment time longer than 10 mins. In short plasma treatment time such as 10 mins, higher colour fading strength can be achieved by increment in both water content and ozone percentage (50\% and $70 \%$ ) in air concentration.

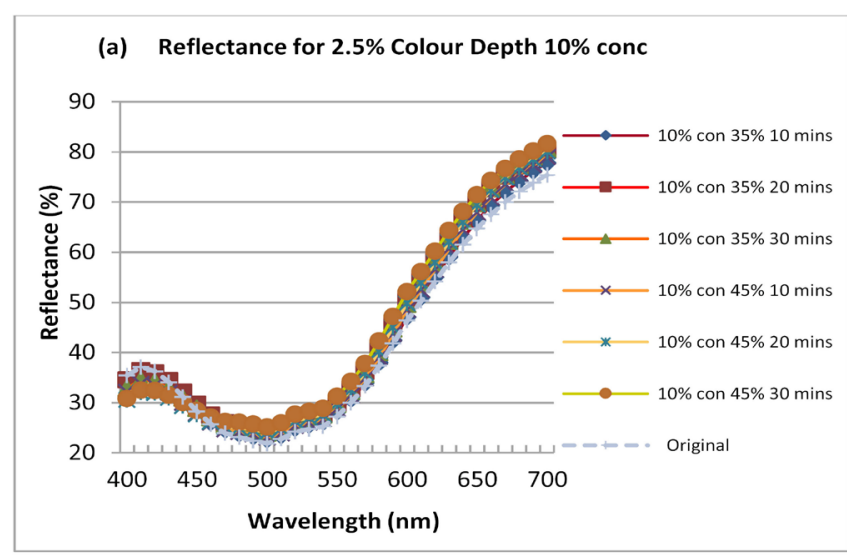

(b) Reflectance for $\mathbf{2 . 5 \%}$ Colour Depth $30 \%$ conc

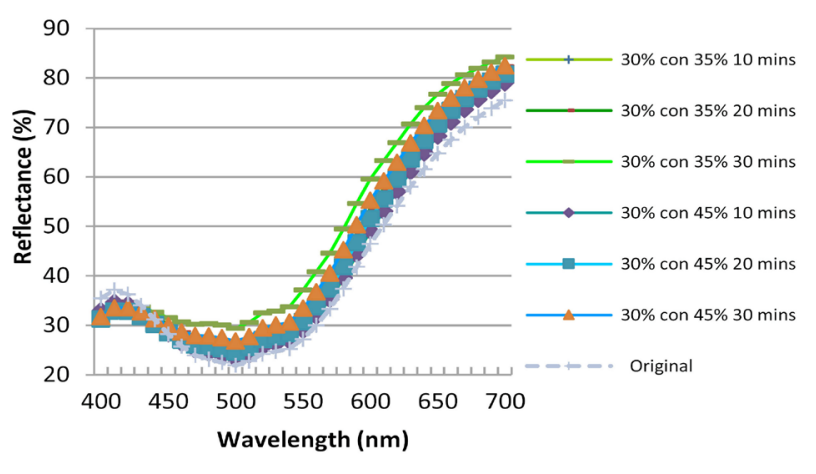

(c) Reflectance for $\mathbf{2 . 5 \%}$ Colour Depth $\mathbf{5 0 \%}$ conc

(d) Reflectance for $2.5 \%$ Colour Depth $70 \%$ conc
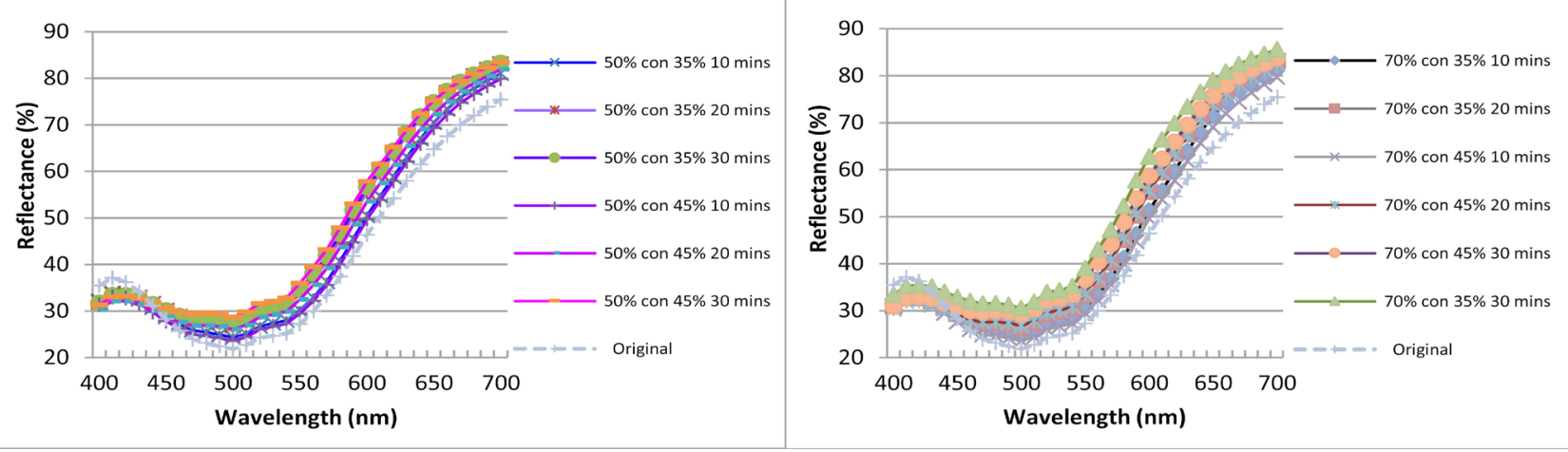

Figure 8. Reflectance Curves of untreated sulfur dyed cotton samples and plasma treated dyed cotton samples in $2.5 \%$ colour depth under various treatment times with air concentration of (a) $10 \%$; (b) $30 \%$; (c) $50 \%$ and (d) $70 \%$. 
Lower water content allows shorter treatment time to yield a comparable or even higher colour fading result rather than longer treatment time with higher water content. Water content affects ozone air concentrations significantly and lower ozone air concentrations retain higher colour fading power compared to higher air concentrations.

\section{2) Effect of Water Content in 1.5\% Colour Depth}

The reduction of colour depth is more likely to be observed under 35\% water content. However, sometimes before it starts to trigger the colour fading reaction, $45 \%$ water content produces slightly lighter samples than $35 \%$. Higher colour fading results from $45 \%$ water content is noticeable from the results with $50 \%$ air concentration. For $50 \%$ air concentration condition, the higher water content (45\%) effect in 30 mins treatments performs twice the effect of lower water content (35\%) in 20 mins treatments.

Lower water content permits shorter treatment time to generate a comparable or even higher colour fading results compared to longer treatment time with higher water content. For instance, sample treated in 10 mins treatment of $10 \%$ air concentration at $35 \%$ water content is lighter than 20 mins treatment of the same air concentration at $45 \%$ water content.

Water content influences ozone air concentrations experimentally and lower air concentrations possess higher colour fading power than higher air concentrations.

\section{3) Effect of Water Content in 2.5\% Colour Depth}

The lightness of cotton fabric after plasma treatment with 35\% water content normally higher than $45 \%$ water content. However, sometimes plasma treatment in $45 \%$ water content produces better decolorized samples than $35 \%$ water content. The reason is that colour fading strengths are dependent on several factors such as optimal ozone air concentration, mass transfer kinetics of reactive oxygen to dyed fabric surface under different water content and time required for ozone dissolution, saturation level and decomposition, etc. These factors are significant in the reaction rate control between decomposed ozone products and dye chromophores on the fabric.

Ozone in air concentration is the key factor for controlling the colour fading effect. The ozone percentage in air concentration is actually affected by water content. Even in the same water content, higher air concentration does not imply higher colour fading strength compared with lower air concentration. Practically, different air concentrations have exhibited different reaction pathways under several parameters including water content and processing time. However, it is quite difficult to generalize the plasma treatment time when the decolorization effect of an ozone air concentration will exceed another ozone air concentration.

From the study of various colour depth groups of cotton fabrics summarized in Tables 2-4, respectively. The general parameters for minimum colour fading strength are $10 \%$ air concentration under both $35 \%$ and $45 \%$ water content, followed by $30 \%$ air concentration under $45 \%$ water content and short processing 
time (10 mins) without apparent change among dyed cotton fabrics. Low reflectance percentages (R\%) observed from the reflectance curves are slightly shift upward than the curves of undyed fabrics. That indicates if the plasma treatment is maintained at $10 \%$ air concentration, the input power for reactive ozone generated is unlikely to remove the dye molecules on the fabric surface.

Other ozone air concentrations possessing higher colour fading strengths include $30 \%$ under $35 \%$ water content, $50 \%$ under $35 \%$ or $45 \%$ water content, and $70 \%$ under $35 \%$ or $45 \%$ water content. Their colour fading strengths vary from time to time and a cycle of change is observed in higher air concentrations. At first, higher ozone air concentration facilitates the mass transfer of ozone from gas phase into liquid phase and lower water content promotes the interaction between ozone and dye chromophores. Secondly, as ozone has attained the saturation level after dissolution in water, there is a reduction in reaction rate between ozone and dye molecules under overdose condition. In contrast, lower ozone air concentration under higher water content $(45 \%)$ has been shown an attenuation in colour fading strength. Higher water content impedes the contact between ozone molecules and dye chromophores and consumes longer time to reach the saturation point. Thirdly, the life cycle of ozone in water medium is shorter than in air and ozone molecules tend to decompose within 20 mins, thus more place will be available for incoming ozone to dissolve. The reaction rate reverts when the water is not in the saturation state. Air concentrations with $35 \%$ or $45 \%$ water content may eventually change the colour fading strengths when the saturation level has not reached.

For cotton fabric with lower dye concentration ( $0.5 \%$ colour depth), the saturation level is easily reached because of small amount of dyes involved in the reaction with ozone. Moreover, lower ozone air concentration or higher water content is more likely to enhance the colour fading effect after decomposition of ozone because the colour fading reaction rate can sustain for longer period before the occurrence of next ozone saturation point. However, higher ozone air concentration is more difficult to maintain high colour fading strength after ozone decomposition. Only a small percentage of ozone is consumed in decolorization and excess amount of ozone will cause another saturation level, which is unfavorable for effective reaction between decomposed ozone and dyes. On the other hand, higher ozone air concentration may facilitate the colour fading reaction rate on fabric with higher dye concentration. It is because a large portion of ozone is consumed in colour fading process.

\section{Conclusions}

Shorter processing time sometimes can yield higher colour fading results than longer plasma processing time upon change of water content.

Lower ozone concentration or higher water content is more likely to enhance the colour fading effect after decomposition of ozone because the colour fading reaction rate can sustain for longer period before the occurrence of next ozone saturation point. 
Higher air concentration accelerates the saturation process and thereby decreasing the colour fading strength. The reflectance curve is more affected when air concentration between $50 \%$ and $70 \%$ as well as treatment time after $30 \mathrm{mi}$ nutes. On the other hand, the reflectance is less affected when air concentration neither below $30 \%$ nor treatment time less than 20 minutes.

\section{Acknowledgements}

The work described in this paper was fully supported by a grant from the Research Grants Council of the Hong Kong Special Administrative Region, China (Project No. UGC/FDS25/E15/17). Authors would like to thank "The Hong Kong Polytechnic University" for technical supports in the project.

\section{Conflicts of Interest}

The authors declare no conflicts of interest regarding the publication of this paper.

\section{References}

[1] Ortiz-Morales, M., Poterasu, M., Acosta-Ortiz, S.E., Compean, I. and Hernandes-Alvarado, M.R. (2003). A Comparison Between Characteristics of Various Laser-Based Denim Fading Processes. Optics and Lasers in Engineering, 39, 15-24. https://doi.org/10.1016/S0143-8166(02)00073-8

[2] Ghoranneviss, M., Shahidi, S., Moazzenchi, B., Anvari, A., Rashidi, A. and Hossenini, H. (2007) Comparison between Decolourization of Denim Fabrics with Oxygen and Argon Glow Discharge. Surface \& Coatings Technology, 201, 4926-4930. https://doi.org/10.1016/j.surfcoat.2006.07.162

[3] Carneiro, N., Souto, A.P., Silva, E., Marimba, A., Tena, B., Ferreira, H. and Maglhaes, V. (2001) Dyeability of Corona-Treated Fabrics. Colouration Technology, 117, 298-302. https://doi.org/10.1111/j.1478-4408.2001.tb00079.x

[4] Morent, R., De Geyter, N., Verschuren, J., De Clerck, K., Kiekens, P. and Leys, C. (2008) Non-Thermal Plasma Treatment of Textiles. Surface \& Coatings Technology, 202, 3427-3449. https://doi.org/10.1016/j.surfcoat.2007.12.027

[5] Radetić, M., Jovancčić, P., Puač, N., Petrović, Z.Lj. and Šaponjić, Z. (2009) Plasma-Induced Decolourization of Indigo-Dyed Denim Fabrics Related to Mechanical Properties and Fiber Surface Morphology. Textile Research Journal, 79, 558-565. https://doi.org/10.1177/0040517508095612

[6] Strickland, A. and Perkins, W. (1995) Decolourization of Continuous Dyeing Wastewater. Textile Chemist and Colourist, 27, 11-15. 